\title{
Tailoring Calcite Growth through an Amorphous Precursor in a Hydrogel Environment
}

Josue A. Lopez-Berganza, Siyu Chen, Rosa M. Espinosa-Marzal

Table S1. Supersaturation $(\sigma)$ with respect to calcite $\left(\sigma_{c}\right)$ and ACC $\left(\sigma_{A C C}\right)$ for selected solution concentrations in equilibrium with atmospheric $\mathrm{CO}_{2}$ at $25^{\circ} \mathrm{C}$. The supersaturation $\sigma=\ln \left(I A P / K_{S}\right)$, where $I A P$ is the ion activity product and $K_{S}$ is the solubility product, was calculated using Visual MINTEQ Version 3.1.

\begin{tabular}{cccc}
\hline $\begin{array}{c}\mathrm{CaCl}_{2} / \mathrm{Na}_{2} \mathrm{CO}_{3} \\
\text { concentration } \\
(\mathrm{mM})\end{array}$ & Reaction $\mathrm{pH}$ & $\sigma_{C}$ & $\sigma_{A C C}$ \\
\hline 4.12 & 8.9 & 4.8 & 0.01 \\
5 & 9.0 & 5.2 & 0.4 \\
15 & 9.0 & 6.9 & 2.1 \\
50 & 9.3 & 8.5 & 3.7 \\
100 & 9.6 & 9.3 & 4.5 \\
200 & 9.7 & 10.2 & 5.3 \\
\hline
\end{tabular}


Table S2. Summary of experimental methods, observables (measurements or simulations) and main insights inferred from this work.

\begin{tabular}{|c|c|c|}
\hline $\begin{array}{l}\text { Experimental } \\
\text { Method }\end{array}$ & Observables & Insights \\
\hline Light Microscopy & $\begin{array}{c}\text { Time resolved imaging of } \\
\text { transformation of ACC to calcite } \\
\text { Calcite growth rate } \\
\text { Number density of calcite } \\
\text { crystals }\end{array}$ & $\begin{array}{c}\text { Formation of ACC as precursor to } \\
\text { calcite } \\
\text { ACC dissolution and reprecipitation } \\
\text { to calcite } \\
\text { Crystal growth rate is independent } \\
\text { of initial ion concentration } \\
\text { Agarose concentration affects } \\
\text { nucleation rate of calcite }\end{array}$ \\
\hline $\begin{array}{c}\text { Light } \\
\text { Spectrophotometry }\end{array}$ & $\begin{array}{c}\text { Kinetics of ACC formation and } \\
\text { dissolution as a function of } \\
\text { supersaturation and agarose } \\
\text { concentration }\end{array}$ & $\begin{array}{l}\text { Attenuation originates from light } \\
\text { scattering by ACC nanoparticles } \\
\text { ACC formation is diffusion limited }\end{array}$ \\
\hline TGA & $\begin{array}{l}\text { Mass percentage of agarose } \\
\text { embedded in calcite } \\
\text { Mineral and organic content of } \\
\text { mineralized hydrogels }\end{array}$ & $\begin{array}{l}\text { ACC-mediated mineralization } \\
\text { results in similar levels of agarose } \\
\text { incorporation in calcite } \\
\text { Amount of embedded agarose in } \\
\text { calcite is larger in } 5 \mathrm{mM} \mathrm{CaCO}_{3}\end{array}$ \\
\hline AFM & $\begin{array}{c}\text { Affinity between calcite and } \\
\text { agarose }\end{array}$ & $\begin{array}{l}\text { The interactions between agarose } \\
\text { hydrogels and calcite are repulsive, } \\
\text { which suggests the action of a } \\
\text { disjoining force during calcite } \\
\text { growth }\end{array}$ \\
\hline SEM & $\begin{array}{l}\text { Imaging of calcite crystals as a } \\
\text { function of agarose and } \mathrm{CaCO}_{3} \\
\text { concentration } \\
\text { Imaging of ACC nanoparticles }\end{array}$ & $\begin{array}{l}\text { Precursor phase consists of } \\
\text { spherical ACC nanoparticles } \\
\text { Non-equilibrium features in calcite } \\
\text { crystals are more obvious in the } \\
\text { absence of ACC precursor }\end{array}$ \\
\hline $\begin{array}{l}\text { XRD and Raman } \\
\text { Spectroscopy }\end{array}$ & $\begin{array}{l}\text { Identification of mineral phases } \\
\text { Spatial mapping of ACC and } \\
\text { calcite during early stages of } \\
\text { mineralization }\end{array}$ & $\begin{array}{c}\text { The precursor phase in this } \\
\text { mineralization pathway is ACC } \\
\text { Calcite is the only crystalline } \\
\text { polymorph }\end{array}$ \\
\hline DLS & $\begin{array}{c}\text { Size distribution of ACC } \\
\text { nanoparticles as a function of } \\
\text { agarose concentration }\end{array}$ & $\begin{array}{c}\text { Particle size is similar or decreases } \\
\text { with increasing agarose } \\
\text { concentration }\end{array}$ \\
\hline $\begin{array}{l}\text { COMSOL Diffusion } \\
\text { Modeling }\end{array}$ & $\begin{array}{l}\text { Simulation of concentration } \\
\text { gradients and calcite growth } \\
\text { during mineralization }\end{array}$ & $\begin{array}{l}\text { The diffusion lengths in the } \\
\text { hydrogels are small enough to } \\
\text { prevent concentration gradients } \\
\text { Calcite growth is consistent with } \\
\text { surface reaction limited growth }\end{array}$ \\
\hline
\end{tabular}



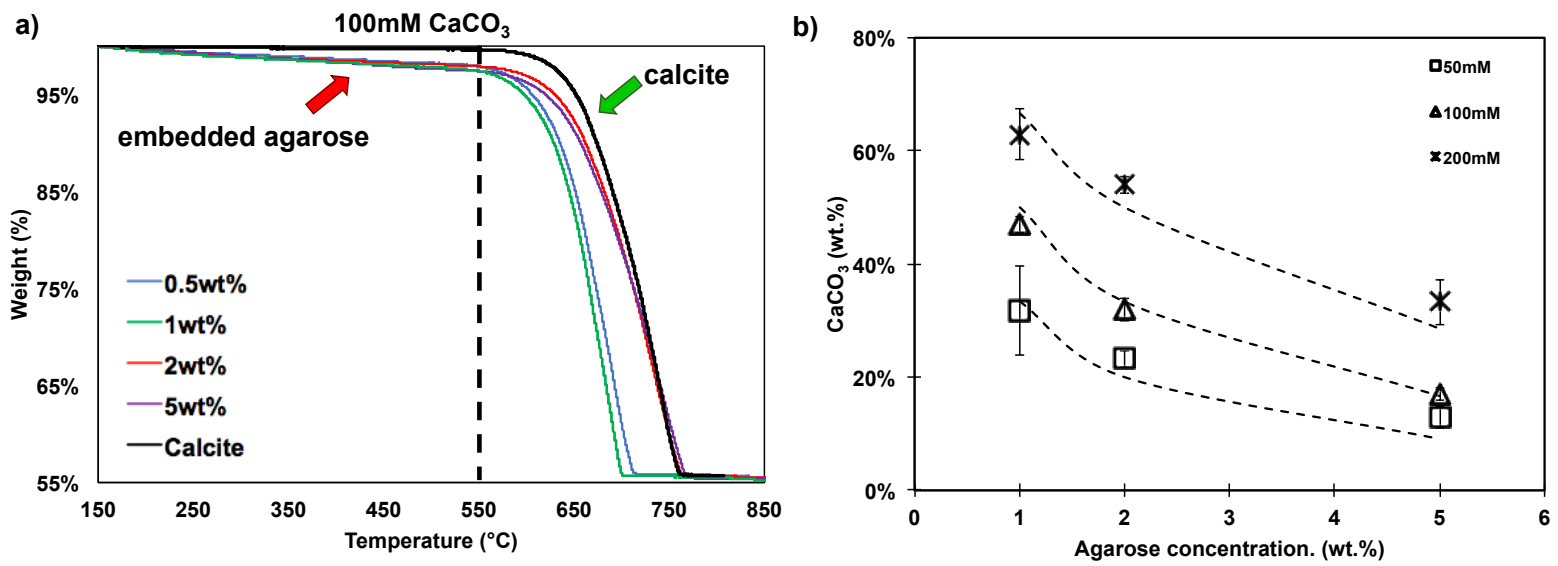

Figure S1. a) Representative thermogravimetric analysis (TGA) of 0.5, 1, 2, 5 wt.\% agarose hydrogels after mineralization in $100 \mathrm{mM} \mathrm{CaCl} / \mathrm{Na}_{2} \mathrm{CO}_{3}$ solution. A small piece of each critically-dried hydrogel after mineralization was thermally decomposed by heating to $900{ }^{\circ} \mathrm{C}$ at $5{ }^{\circ} \mathrm{C} \mathrm{min}^{-1}$. The dashed line distinguishes the weight loss due to agarose and to calcite. The weight percentage of $\mathrm{CaCO}_{3}$ was obtained from the measured weight loss above a temperature of $550^{\circ} \mathrm{C}$. b) Weight percentage of calcium carbonate in critically-dried hydrogels as a function of the agarose concentration measured by TGA. The dashed lines represent the calculated stoichiometric weight percentage of $\mathrm{CaCO}_{3}$ in the agarose hydrogels according to the initial concentration of the solutions.
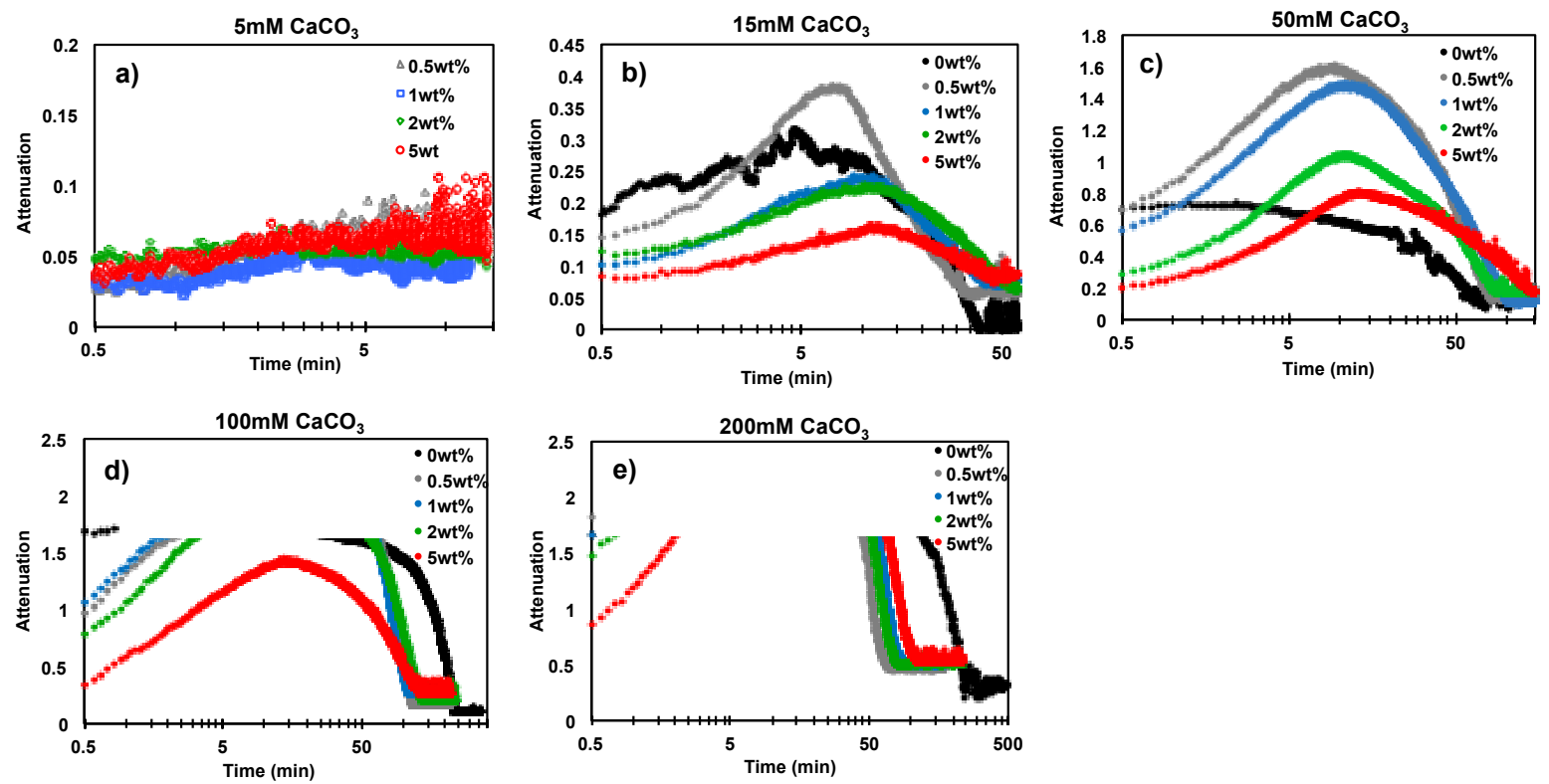

Figure S2. Representative attenuation measurements during $\mathrm{CaCO}_{3}$ mineralization at the $\mathrm{CaCl}_{2} / \mathrm{Na}_{2} \mathrm{CO}_{3}$ concentrations of a) $5 \mathrm{mM}$ b) $15 \mathrm{mM}$, c) $50 \mathrm{mM}$, d) $100 \mathrm{mM}$ and e) $200 \mathrm{mM}$ in agarose hydrogels with different concentrations $(0.5-5 \mathrm{wt} . \%)$. Transparent white boxes in d) and e) indicate that the loss of sensitivity of the spectrometer due to the high turbidity of the samples. 

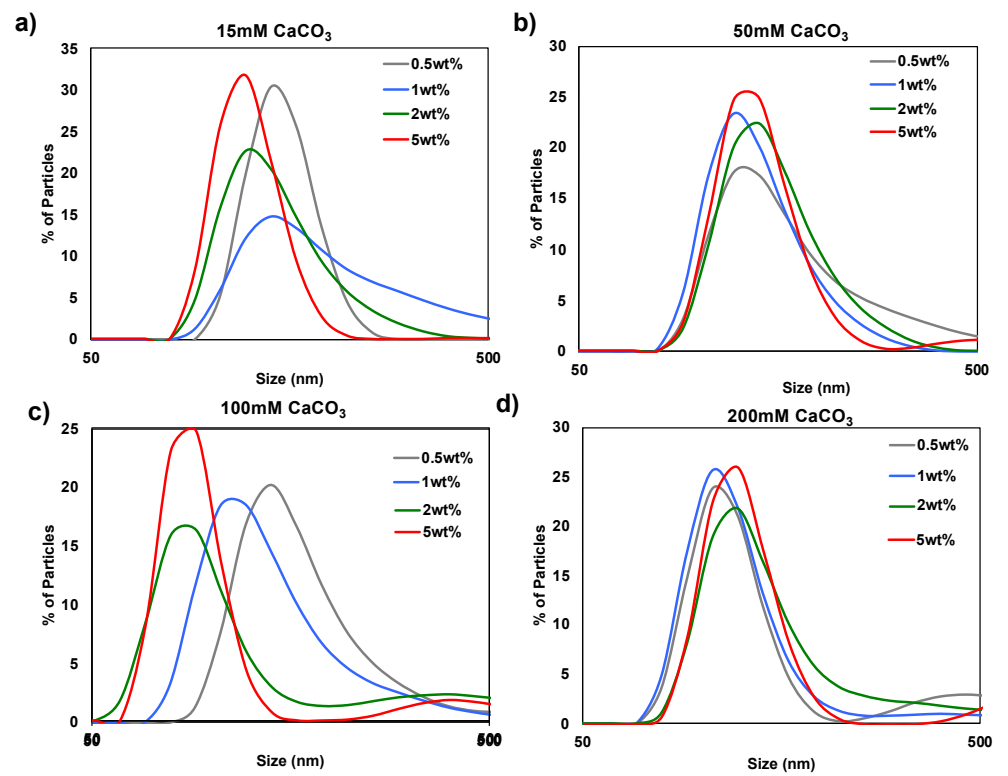

e)

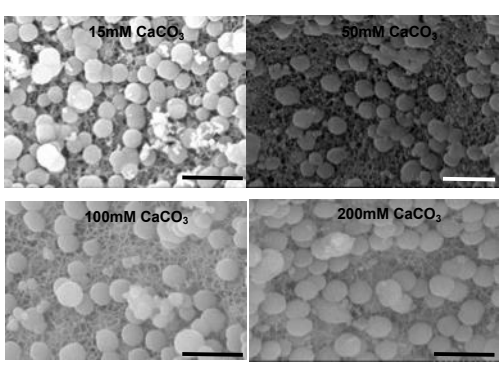

f)

$\mathrm{CaCO}_{3}$ Concentration

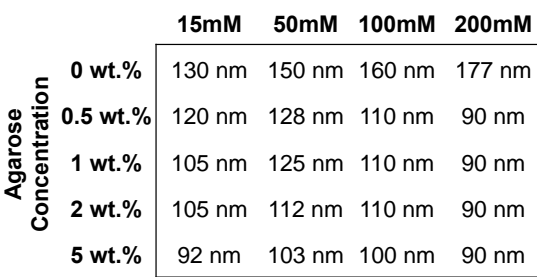

Figure S3. Size distribution of ACC nanoparticles in hydrogels with agarose concentrations of $0.5,1,2$ and 5 wt. $\%$ at $\mathrm{CaCl}_{2} / \mathrm{Na}_{2} \mathrm{CO}_{3}$ concentrations of a) $15 \mathrm{mM}$, b) $50 \mathrm{mM}$, c) $100 \mathrm{mM}$ and d) $200 \mathrm{mM}$ after 6 minutes of mineralization. The same measurements were also conducted after 3 minutes of mineralization but the difference in the distribution is not statistically significant. e) SEM images of ACC particles precipitated in $5 \mathrm{wt} \%$ agarose hydrogels at different $\mathrm{CaCO}_{3}$ concentrations. The diameter agrees well with the DLS measurement. f) Average size used for the estimation of the mass of ACC per unit volume of hydrogel. Scale bar $=500 \mathrm{~nm}$.
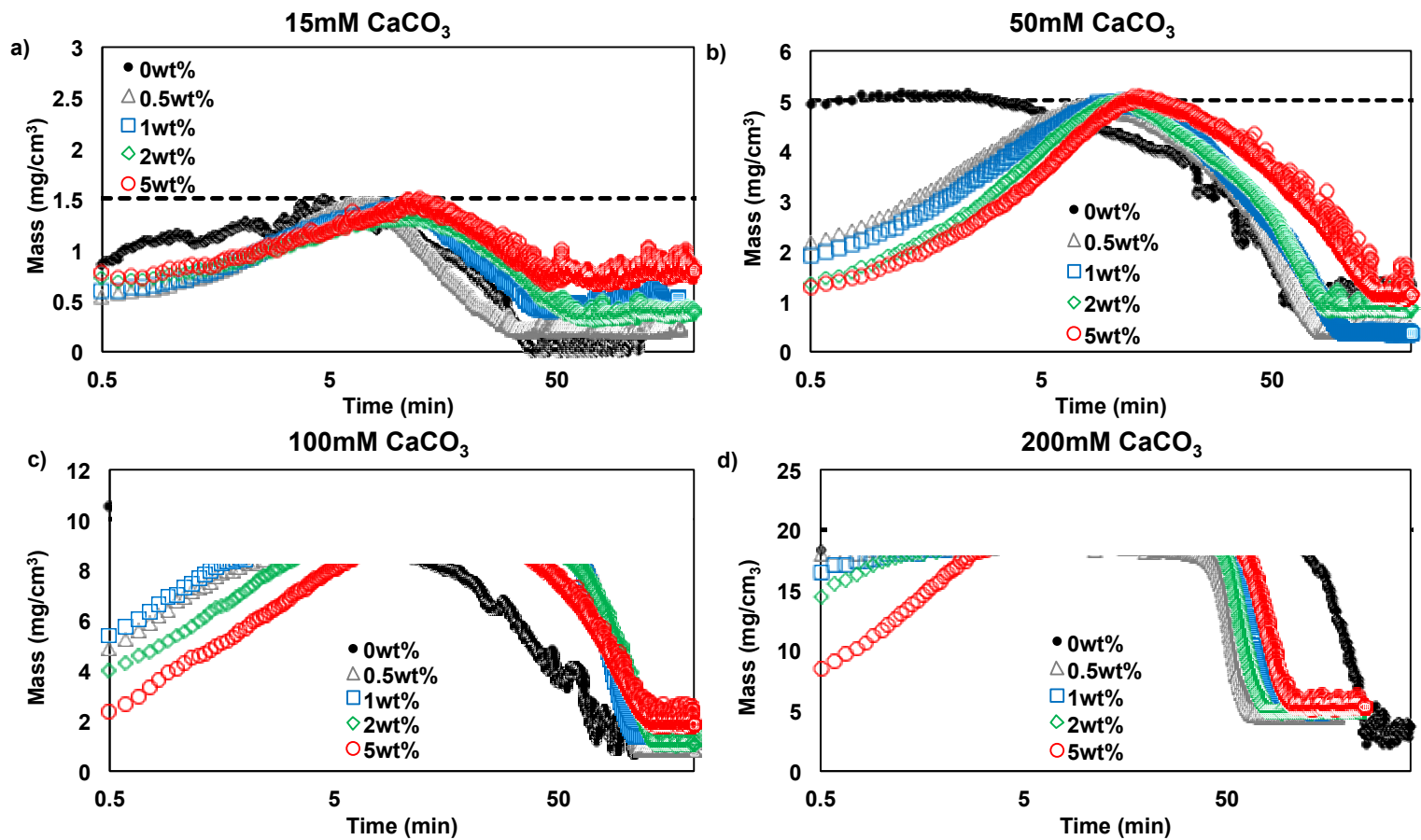

Figure S4. ACC mass per unit volume as a function of time in agarose hydrogels at $\mathrm{CaCl}_{2} / \mathrm{Na}_{2} \mathrm{CO}_{3}$ concentrations of a) $15 \mathrm{mM}$, b) $50 \mathrm{mM}$, c) $100 \mathrm{mM}$ and d) $200 \mathrm{mM}$. The formation rate of ACC was determined by linear fits to the initial rise and final decrease attenuation. At attenuations above 1.6 (achieved at the $\mathrm{CaCO}_{3}$ concentrations of $100 \mathrm{mM}$ and 
$200 \mathrm{mM}$ ), the signal-to-noise ratio is reduced by the high turbidity of the sample, and therefore, the spectrophotometer becomes less sensitive to changes in the mass and it appears as a plateau (region marked by a transparent white box) that underestimates the precipitated mass. Black markers represent the reference measurements in the absence of the hydrogel. The dashed black line shows the stoichiometric mass of ACC that can precipitate in the hydrogels.

a)

c)
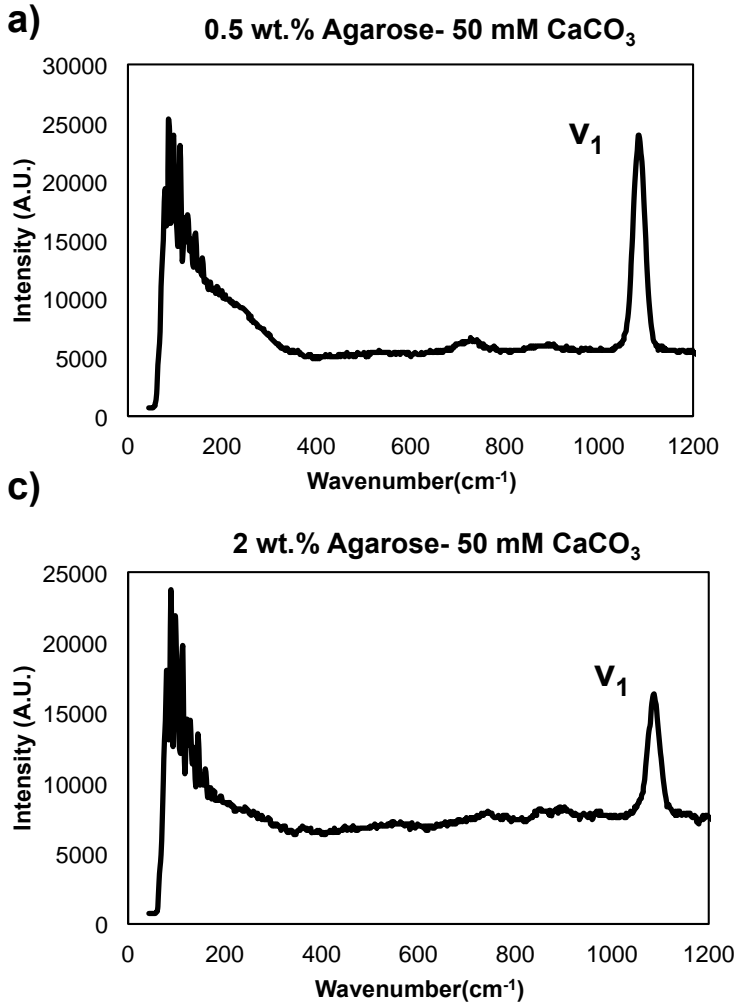

e)

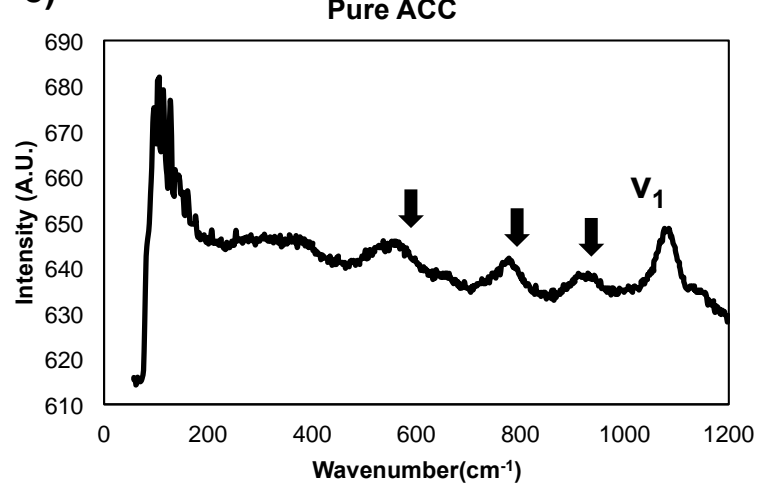

b)
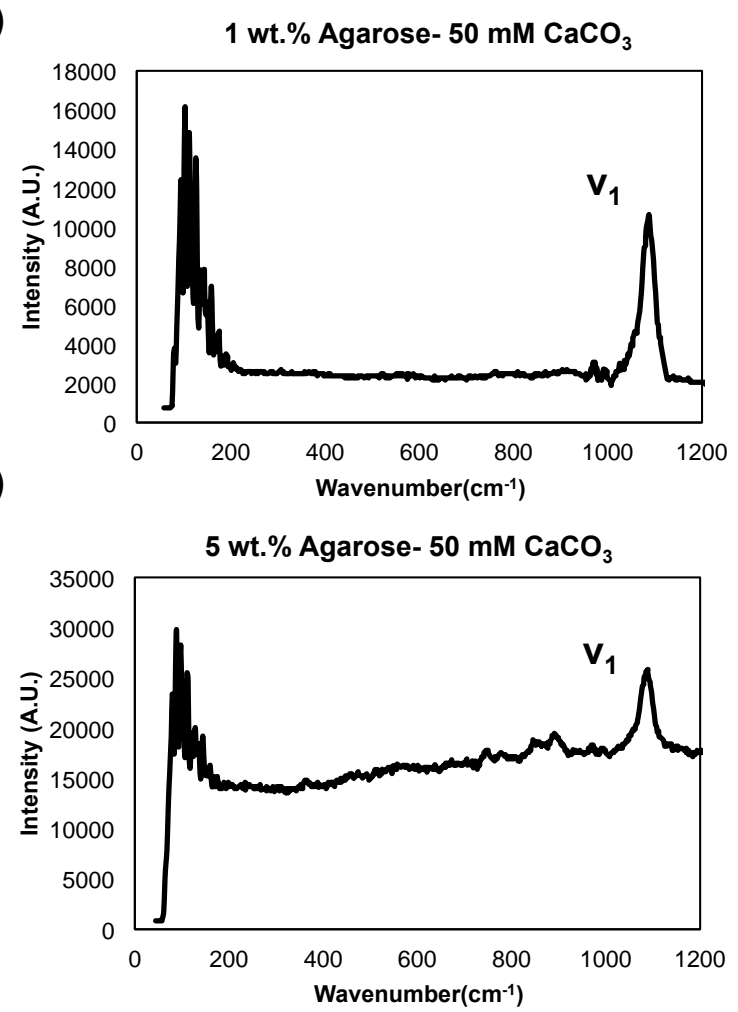

Figure S5. a-d) Raman microspectroscopy of the agarose hydrogels after 3 minutes of mineralization at the $\mathrm{CaCl}_{2} / \mathrm{Na}_{2} \mathrm{CO}_{3}$ concentration of $50 \mathrm{mM}$. The mineralized hydrogels were immersed in pure ethanol to quench the reaction and to exchange water with ethanol. Once the exchange of water by ethanol was complete, the hydrogels were critically-dried and immediately analyzed under Raman spectroscopy. The broadened band at $1085 \mathrm{~cm}^{-1}\left(v_{1}\right)$ unequivocally demonstrates the presence of ACC. e) Reference ACC was synthesized in the absence of a hydrogel by mixing equimolar $\mathrm{CaCl}_{2}$ and $\mathrm{Na}_{2} \mathrm{CO}_{3}$ solutions, filtered and washed with ethanol and dried in a desiccator for 12 hours. After drying, ACC was placed on a fused silica glass slide. Black arrows represent the fused silica signals of the substrate. 

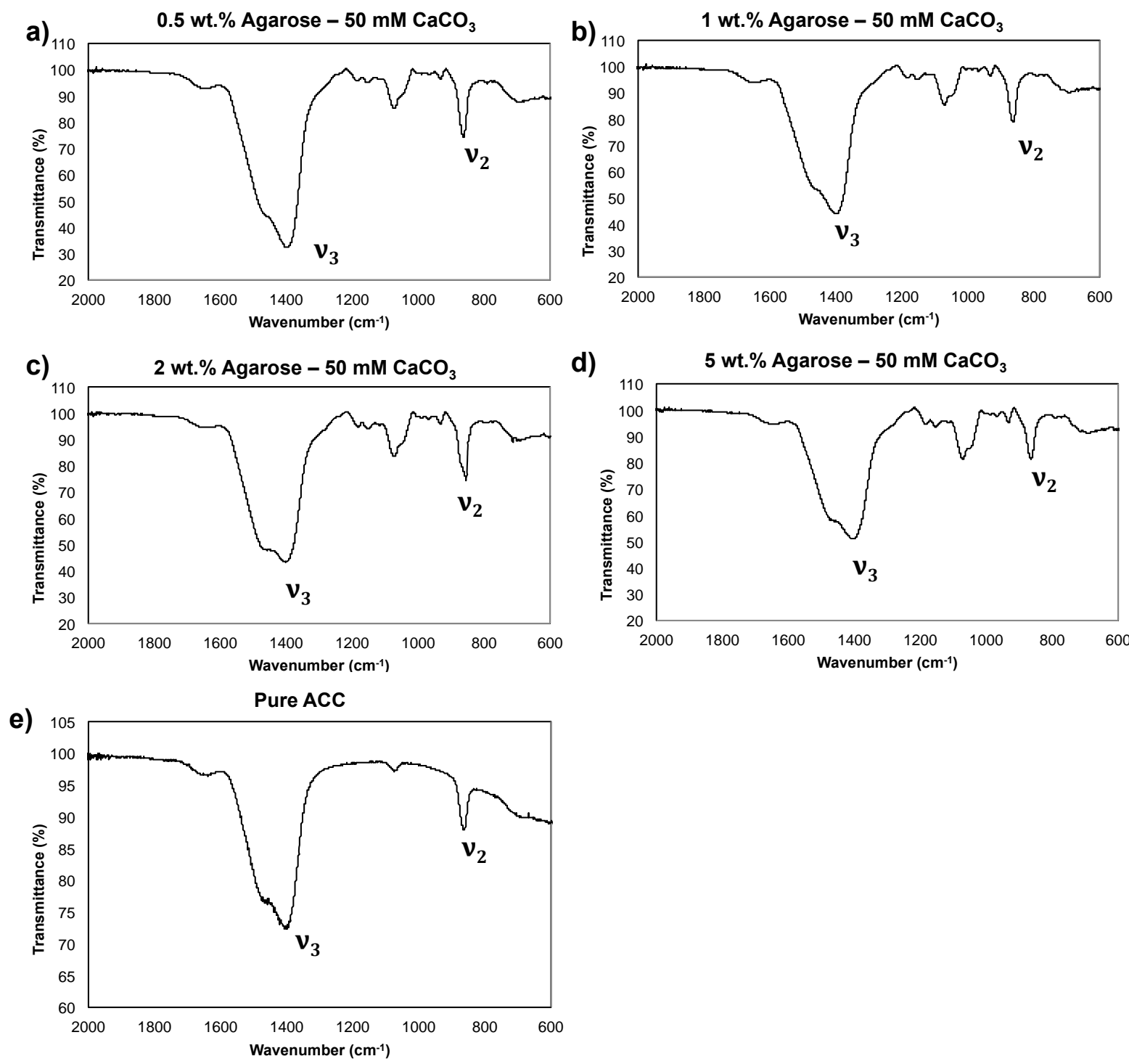

Figure S6. a-d) FT-IR spectra of the agarose hydrogels after 3 minutes of mineralization at the $\mathrm{CaCl}_{2} / \mathrm{Na}_{2} \mathrm{CO}_{3}$ concentration of $50 \mathrm{mM}$. After mineralization, the hydrogels were immersed in pure ethanol to quench the reaction and to exchange water with ethanol. Once the exchange of water by ethanol was complete, the hydrogels were critically-dried and immediately analyzed by FT-IR. A broadened peak at $866 \mathrm{~cm}^{-1}\left(v_{2}\right)$ and a split peak at $1400 \mathrm{~cm}^{-1}\left(v_{3}\right)$ indicate that ACC is the dominant phase. e) Reference ACC (see Figure S5) after 12 hours in desiccator. 
a)

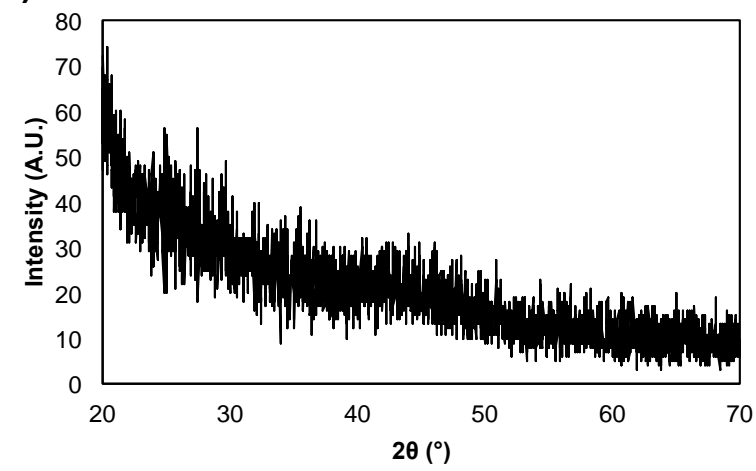

c)

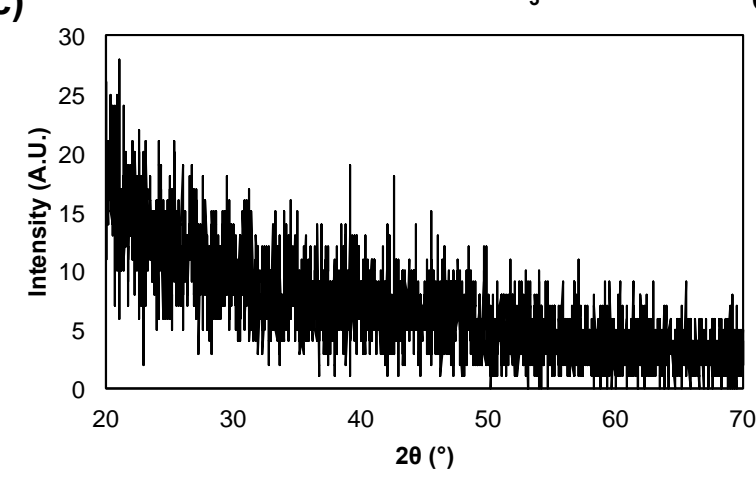

e)

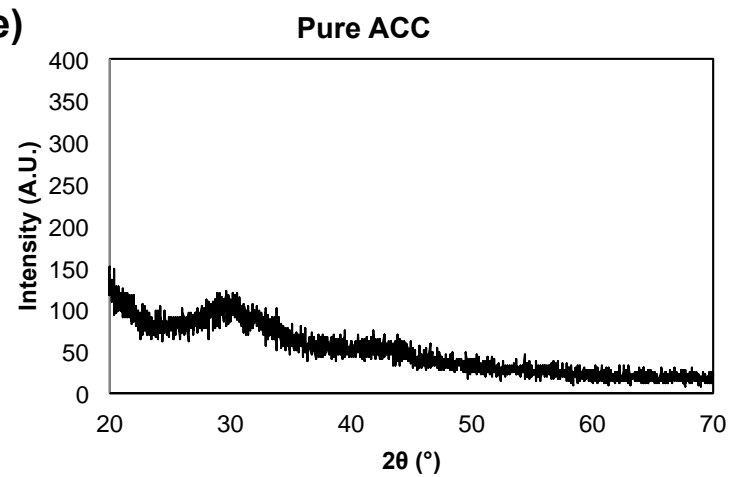

b)

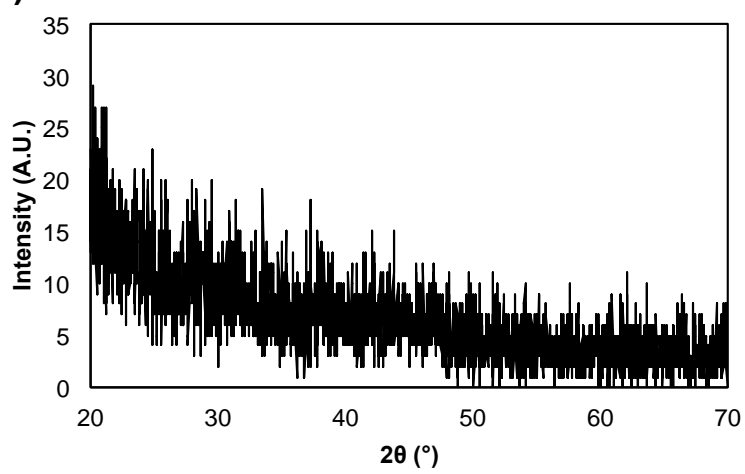

d)

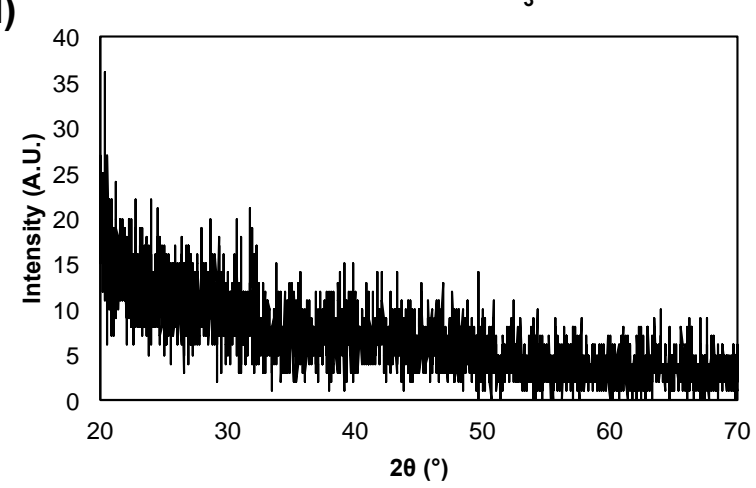

Figure S7. a-d) XRD diffractograms of the agarose hydrogels after 3 minutes of mineralization at the $\mathrm{CaCl}_{2} / \mathrm{Na}_{2} \mathrm{CO}_{3}$ concentration of $50 \mathrm{mM}$. After mineralization, the hydrogels were immersed in pure ethanol to quench the reaction and to exchange water with ethanol. Once the exchange of water by ethanol was complete, the hydrogels were criticallydried and immediately analyzed by XRD. e) Reference ACC (see caption of Figure S5). 
a)

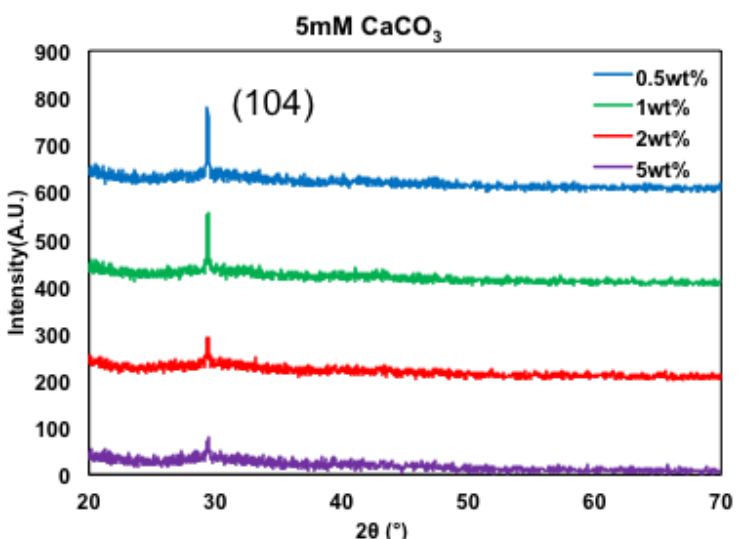

c)

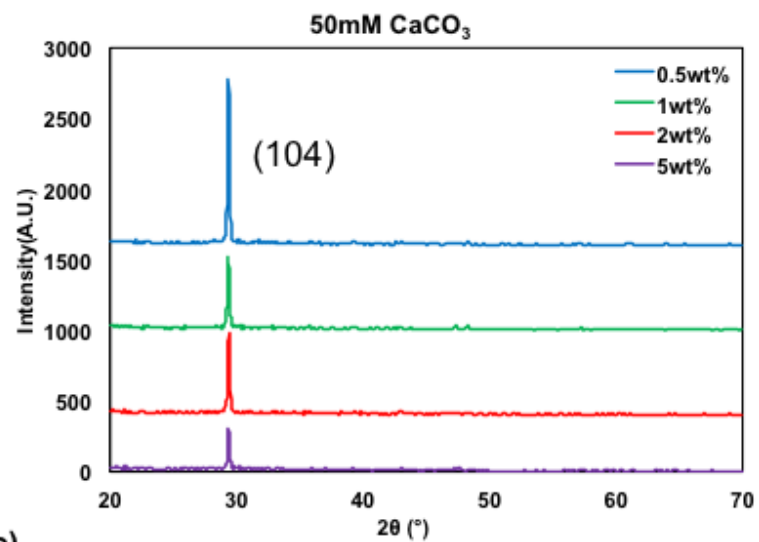

e)

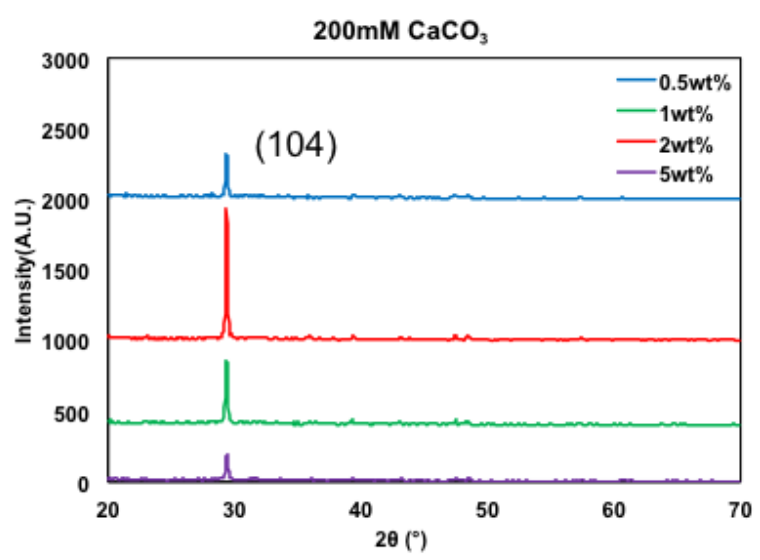

b)

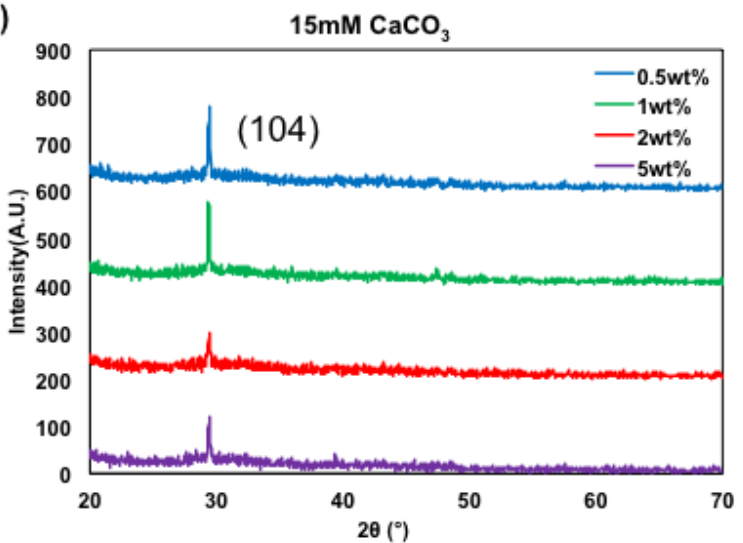

d)

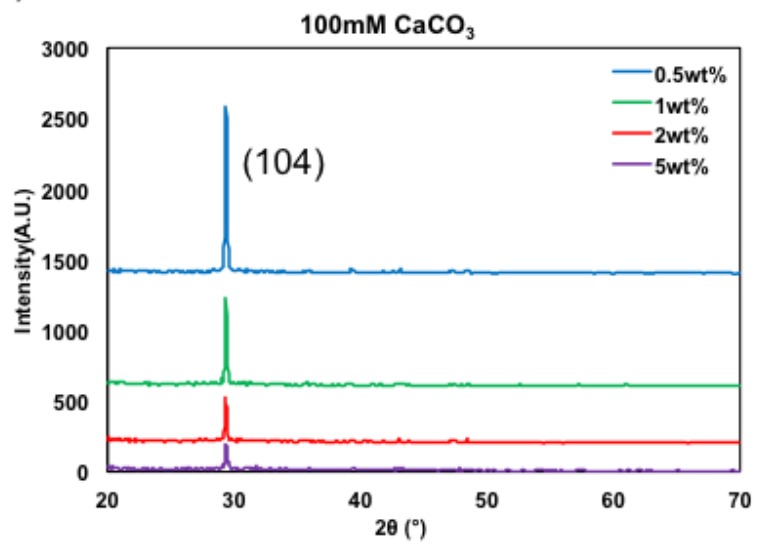

Figure S8. X-ray powder diffraction (XRD) diffractograms of the precipitated solid in $0.5,1$, 2 and 5 wt. $\%$ agarose hydrogels at the selected $\mathrm{CaCl}_{2} / \mathrm{Na}_{2} \mathrm{CO}_{3}$ concentrations. After mineralization, the hydrogels were immersed in boiling water to melt the agarose and isolate the precipitated solid. A prominent peak is observed at $29^{\circ}$ corresponding to the $\left(\begin{array}{lll}1 & 0 & 4\end{array}\right)$ plane of calcite in all cases. No peaks associated with vaterite or aragonite were observed. 


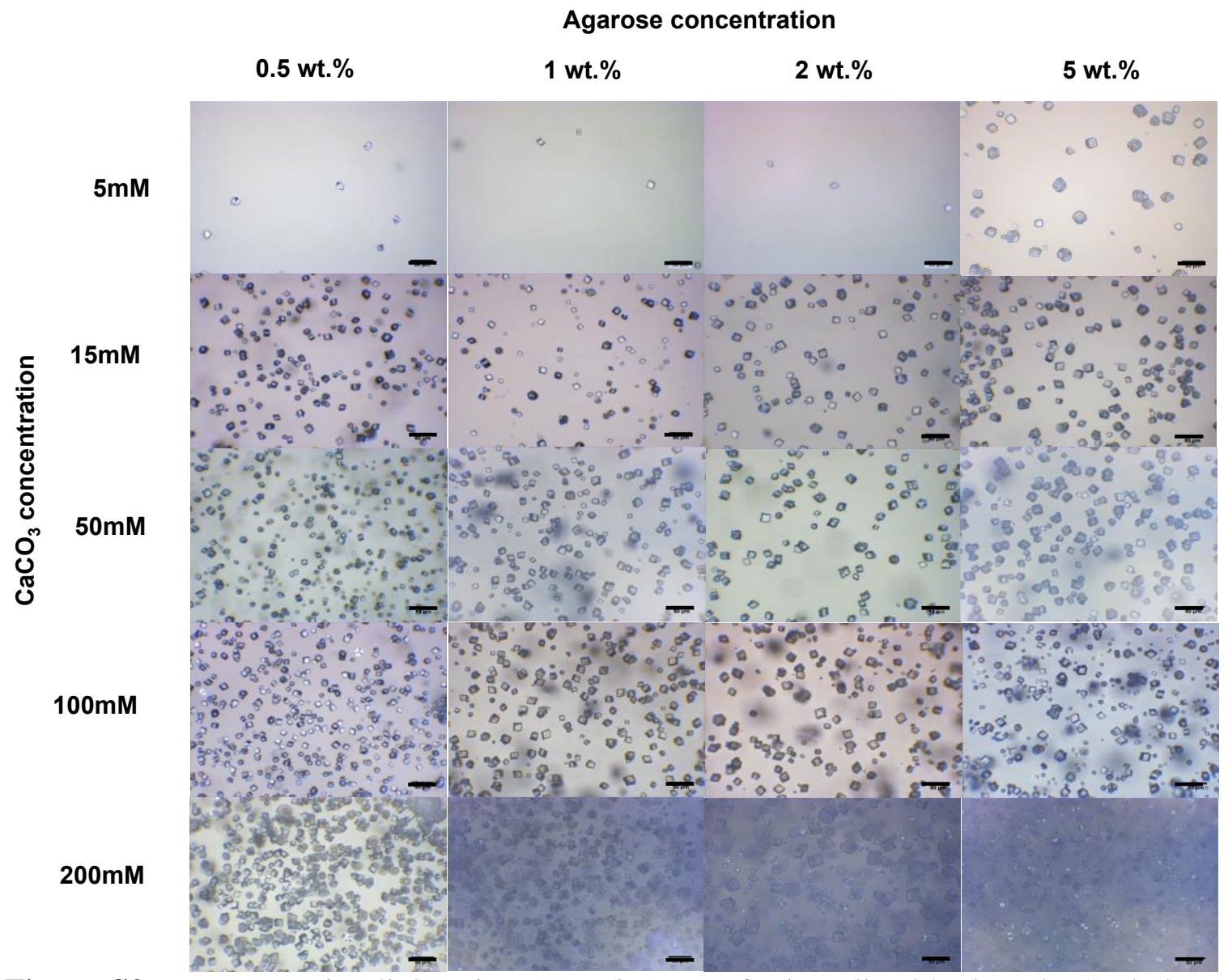

Figure S9. Representative light microscopy images of mineralized hydrogels. Scale bar $=50$ $\mu \mathrm{m}$. 


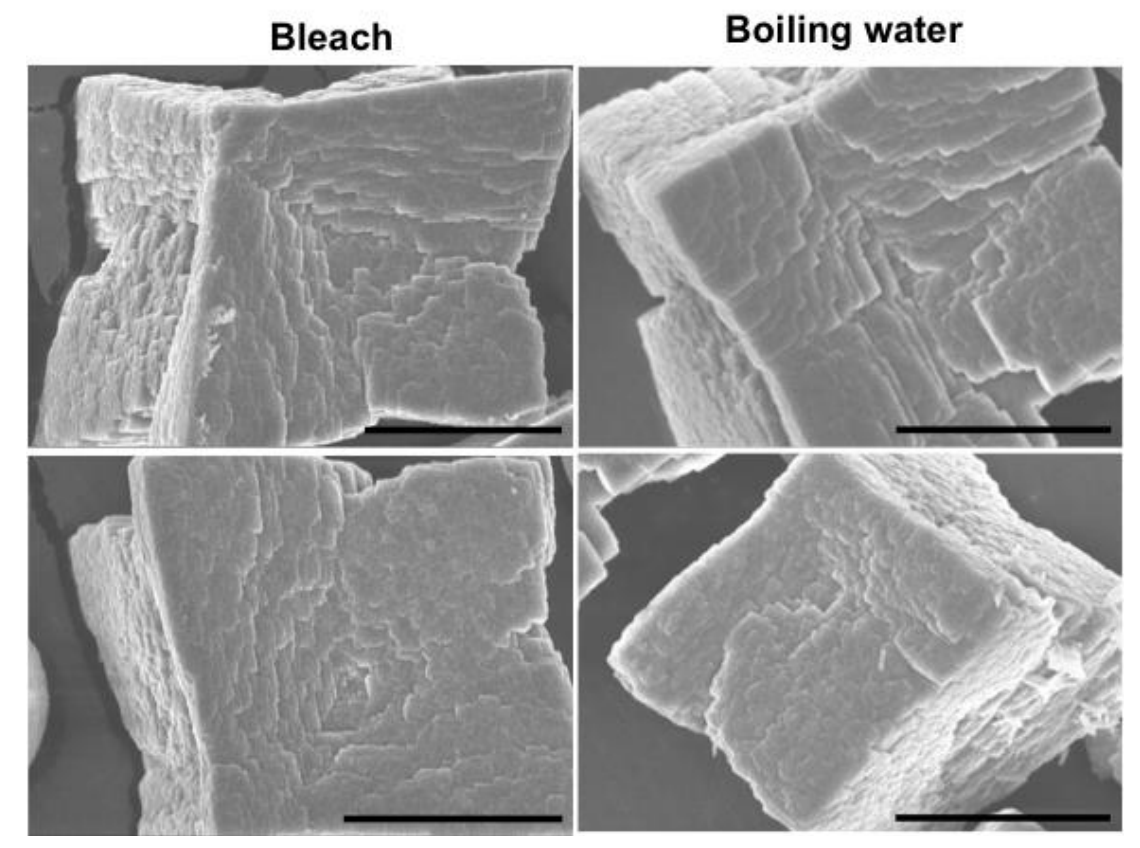

Figure S10. Calcite crystals isolated from 2 wt.\% agarose hydrogels precipitated in $\mathrm{CaCl}_{2} / \mathrm{Na}_{2} \mathrm{CO}_{3}$ solution at the concentration of $100 \mathrm{mM}$. The crystals shown in the left column were filtered after incubation in a $5 \%$ sodium hypochlorite solution at $65^{\circ} \mathrm{C}$ to digest the agarose network. The crystals on the right column were filtered after melting the agarose in boiling water. The similarity of the crystal features demonstrates that boiling water does not affect the morphology of the crystals compared to a chemical treatment at a milder temperature. Scale bar $=10 \mu \mathrm{m}$.
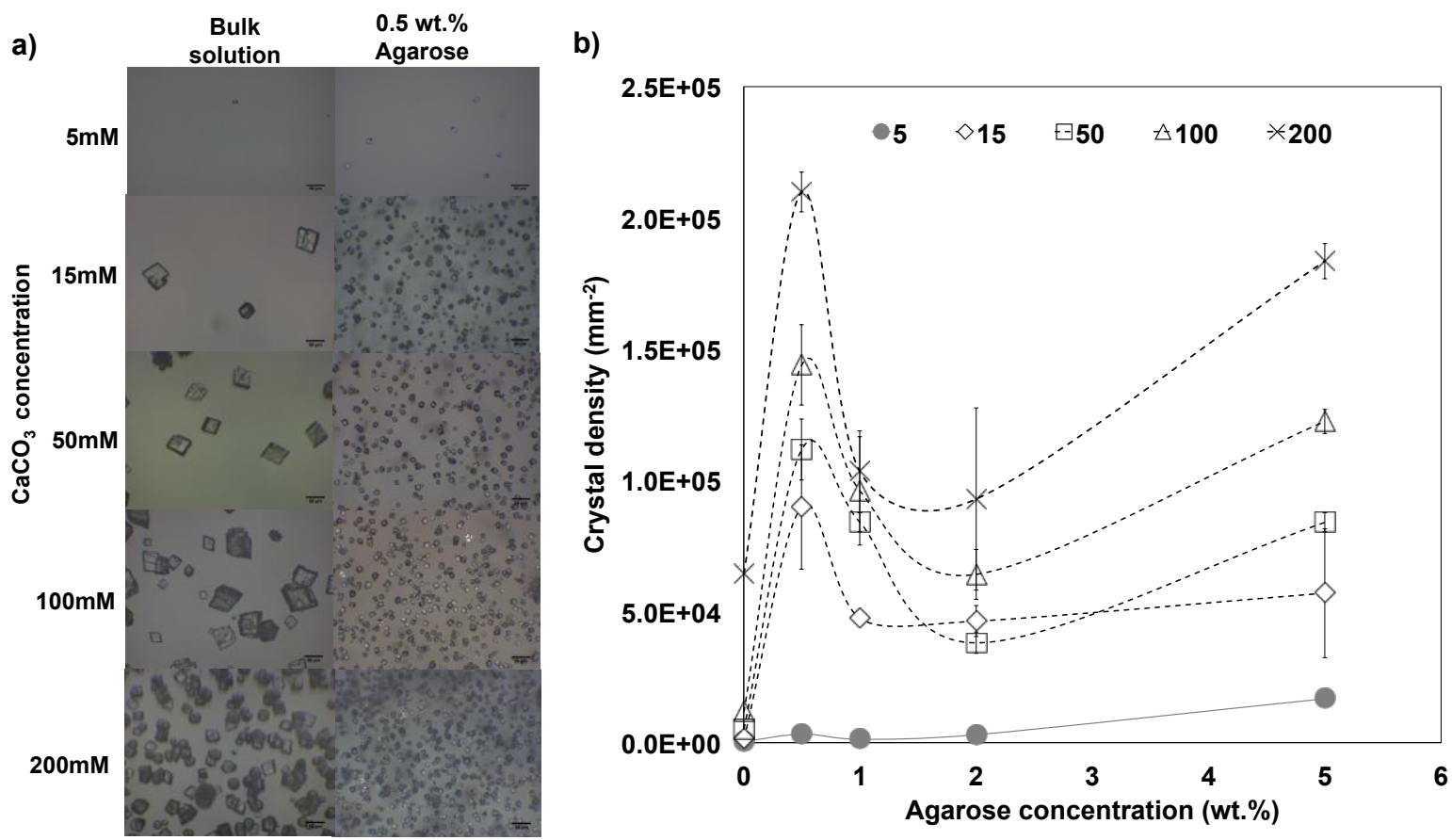

Figure S11. a) Light microscopy images of calcite precipitated in the bulk solution (left column) and in $0.5 \mathrm{wt} . \%$ agarose hydrogels (right column) at three different $\mathrm{CaCl}_{2} / \mathrm{Na}_{2} \mathrm{CO}_{3}$ concentrations, demonstrating that the hydrogel promotes the nucleation of calcite. B) Number density of calcite crystals per unit area in the absence of hydrogel $(0 \mathrm{wt} . \%)$ and in the hydrogels at the different $\mathrm{CaCl}_{2} / \mathrm{Na}_{2} \mathrm{CO}_{3}$ concentrations $(5,15,50,100$ and $200 \mathrm{mM})$. 